\title{
A CONTRIBUIÇÃO DA EXPERIÊNCIA SENSORIAL NA CONSTRUÇÃO DAS INTERFACES DIGITAIS ACESSÍVEIS AOS DEFICIENTES VISUAIS
}

\section{THE CONTRIBUTION OF THE SENSORY EXPERIENCE IN THE CONSTRUCTION OF DIGITAL INTERFACES ACCESSIBLE TO VISUAL DISABILITIES}

\author{
Marilu Donadeli Vecchio ${ }^{1}$, Esp. \\ Raul Inácio Busarello², D.Sc.
}

(1) Centro Universitário Belas Artes de São Paulo mvecchio7@gmail.com

(2) Centro Universitário Belas Artes de São Paulo

busarello.belasartes@gmail.com

Experiência Sensorial, Deficiência Visual, Interfaces Digitais Acessíveis.

O objetivo deste artigo é apresentar as percepções obtidas na experiência de um designer digital, quando inserido em um ambiente que simula a falta de visão. Metodologicamente segue a pesquisa qualitativa exploratória, aplicada com a técnica imersiva etnográfica. Como resultado, foi constatado que os dispositivos móveis trouxeram uma nova perspectiva na vida das pessoas com deficiência visual. A interação com interfaces computacionais facilitam a comunicação e a mobilidade. A possibilidade de explorar interfaces por meio do tato, com o auxílio de informações sonoras, permitem uma melhoria na transmissão do conhecimento.

Sensory Experience. Visual impairment. Accessible Digital Interfaces.

The purpose of this article is to present the perceptions obtained in the experience of a digital designer, when inserted in an environment that simulates the lack of vision. Methodologically follows the exploratory qualitative research, applied with the immersive ethnographic technique. As a result, it has been found that mobile devices have brought a new perspective on the lives of people with visual impairments. Interaction with computational interfaces facilitates communication and mobility. The possibility of exploring interfaces through tact, with the aid of sound information, allows an improvement in the transmission of information. 
$16^{\circ}$ Ergodesign - Congresso Internacional de Ergonomia e Usabilidade de Interfaces Humano Tecnológica: Produto, Informações Ambientes Construídos e Transporte

$16^{\circ}$ USIHC - Congresso Internacional de Ergonomia e Usabilidade de Interfaces Humano Computador

CINAHPA | 2017 - Congresso Internacional de Ambientes Hipermídia para Aprendizagem.

\section{Introdução}

O objetivo deste artigo é relatar as percepções extraídas da experiência sensorial, em ambiente simulado, a fim de embasar e de estimular os designers digitais quanto ao entendimento das necessidades dos deficientes visuais, com o intuito de fundamentar o desenvolvimento de propostas e soluções acessíveis, e que contribuam para tornar mais digna e cômoda as atividades do dia a dia das pessoas cegas.

Esta pesquisa é parte integrante de um projeto

maior em fase embrionária, que pretende explorar soluções adaptáveis no uso da audiodescrição inserida em publicações digitais. Com o propósito de democratizar o acesso à informação, objetivando a inclusão digital.

Para construir esta análise, foi utilizado o processo criativo descrito na metodologia projetual de Munari (2000). Em seu método (Ibidem), aborda onze fases: 1. Problema; 2. Definição do problema; 3. Componentes do problema; 4. Coleta de dados; 5. Análise de dados; 6. Criatividade; 7. Materiais e tecnologia; 8. Experimentação; 9. Modelo; 10. Verificação; 11. Solução.

$\mathrm{Na}$ fase de "identificação do problema", Munari (2000) parte do princípio que, o usuário é o principal foco da realização de um produto, e prioriza as suas necessidades, os seus desejos, as suas expectativas e os seus condicionamentos. Em cada etapa do projeto, designers e projetistas consultam pessoas, representativas dos usuários finais, para conhecê-los em profundidade e aliar técnica e sensibilidade para resultados que criem empatia e identidade.

A fim de obter maior entendimento sobre o usuário final neste caso, buscou-se conhecer as causas da deficiência visual, que ocorre quando há perda total ou parcial da visão de forma congênita ou adquirida. De acordo com o Relatório Mundial sobre a Deficiência da Organização Mundial da Saúde (OMS, 2013), se caracteriza baixa visão quando a deficiência visual pode ser compensada pelo uso de acessórios, como lentes de aumento.
De forma contrária, a cegueira é caracterizada pela perda total da visão ou quando a capacidade de enxergar é quase nula. Segundo a Organização Mundial da Saúde (2013), considera-se cegueira quando o valor da acuidade visual corrigida no melhor olho é menor do que 0,05 ou o campo visual menor do que $10^{\circ}$.

Segundo Júnior (2013), da Rádio ONU em Nova York, em notícia publicada em outubro de 2013, a OMS afirma que existem 39 milhões de pessoas cegas no mundo, e que 246 milhões sofrem limitações severas na visão. Além disso, $90 \%$ dos casos de cegueira ocorrem em países emergentes e subdesenvolvidos e preveem que até 2020 , o número de pessoas com deficiência visual poderá dobrar no planeta. No Brasil, entre todas as deficiências, a visual foi a que mais apareceu entre as respostas dos entrevistados do Censo Demográfico 2010, realizado pelo Instituto Brasileiro de Geografia e Estatística (OLIVEIRA, 2010). A região Nordeste possui o maior número de pessoas que confirmaram portar algum tipo de deficiência visual, $4,1 \%$ da população.

Com a finalidade de promover a dignidade da pessoa humana e os direitos fundamentais como garantia da inclusão social, o Programa de Ação Mundial para Pessoas com Deficiência (ONU, 1982), propôs medidas eficazes para prevenção da deficiência e para reabilitação dos objetivos de igualdade e da participação plena das pessoas com deficiência na vida social.

\section{A Percepção e a Rotina do Cego}

A percepção dos indivíduos se dá por meio dos sentidos. Eles são cinco: a Visão, o Paladar, o Olfato, o Tato e a Audição. Estas percepções nos permitem formar ideias, imagens e compreender o mundo que nos rodeia. Tuan (1980) ressalta em sua obra "Topofilia", que dos cinco sentidos tradicionais, o homem depende mais conscientemente da visão do que dos demais sentidos para referenciar o mundo. O homem é predominante animal movido pelo visual.

De acordo com Goldreich (2015), pessoas cegas de nascença são capazes de detectar com maior 


\section{$16^{\circ}$ \\ ERGODESIGN USIHC CINAHPA}

rapidez informações táteis do que as pessoas videntes. Isso porque o cérebro exige uma fração de segundo para registrar uma visão, um som ou um toque. Segundo o autor, o cérebro se adapta à ausência de visão acelerando o sentido de toque, como numa espécie de compensação sensorial.

No que diz respeito à acessibilidade, o Decreto Federal $n^{\circ} 5.296 / 2004$ no artigo $8^{\circ}$ estabelece que a acessibilidade é, condição para utilização, com segurança e autonomia, total ou assistida, dos espaços, mobiliários e equipamentos urbanos, das edificações dos serviços de transporte e dos dispositivos, dos sistemas e dos meios de comunicação e da informação, por pessoa portadora de deficiência ou com mobilidade reduzida (BRASIL, 2004). A tecnologia torna a vida das pessoas mais fácil. Como mostra o coordenador do Centro de Engenharia de Reabilitação e Acessibilidade (GODINHO, 1999).

Segundo Vergara-Nunes (2011), a pessoa cega possui hábitos diferentes das demais. Comporta-se de outra forma, isso porque sua rotina é bem distinta em relação às pessoas que têm visão. Os olhos do cego são os dedos das mãos, os ouvidos, a bengala e os olhos de outra pessoa. E é a partir dessas particularidades que os cegos enfrentam diversos desafios diariamente. Atravessar uma rua, tomar um banho ou até mesmo amarrar os cadarços dos sapatos são situações aparentemente simples para quem nasceu e permanece enxergando, mas ao contrário de quem tem visão, é preciso uma reabilitação para se adequar a essas e outras atividades. Em ocasiões específicas, as pessoas cegas e com baixa visão dependem de terceiros e de tecnologia assistiva para auxiliar na identificação de ruas, de itinerários de ônibus, de obstáculos e de outras referências visuais.

Galvão Filho (2009) define tecnologia assistiva "como qualquer recurso, produto ou serviço que favoreça a autonomia, a atividade e a participação da pessoa com deficiência". Na mesma linha, "Todo o arsenal de recursos e serviços que contribuem para proporcionar ou ampliar habilidades funcionais de pessoas com deficiência e consequentemente promover vida independente e inclusão" (BERSCH, 2008, p. 2). $16^{\circ}$ Ergodesign - Congresso Internacional de Ergonomia e Usabilidade de Interfaces Humano Tecnológica: Produto, Informações Ambientes Construídos e Transporte

$16^{\circ}$ USIHC - Congresso Internacional de Ergonomia e Usabilidade de Interfaces Humano Computador

CINAHPA | 2017 - Congresso Internacional de Ambientes Hipermídia para Aprendizagem.
Alguns recursos de tecnologia assistiva, mesmo que de forma muito acanhada, já estão em uso no Brasil. Fora do país existem muitos estudos sobre os recursos tecnológicos utilizando inclusive o auxílio das redes sociais.

Dos recursos utilizados para o deslocamento, segundo Hoffmann (1999), a bengala é o principal recurso usado pelos deficientes visuais. No entanto, o uso exclusivo da bengala, ou mesmo do cão-guia, não dispensa a eventual colaboração de guias humanos ou de informantes. Ainda que seja apenas para atravessar ruas, para parar um ônibus ou táxi, para prevenir acidentes ocasionais ou, simplesmente, para facilitar o acesso entre outras possibilidades de interação.

O guia humano é uma pessoa que estaria disponível para desempenhar, de forma voluntária ou profissional, a função de acompanhar pessoas cegas em sucessivos deslocamentos, apoiando-as na realização de tarefas e nos expedientes eminentemente visuais.

O cão-guia é outro auxílio à locomoção, mas por ser um recurso oneroso, seu acesso ainda é restrito. Além das dificuldades na aceitação social, no Brasil, a Lei 188/99 de 14 de abril regulariza o uso de cães-guia por meio de regras jurídicas destinadas a facilitar a missão do acompanhamento. O pleno cumprimento da atividade que os mesmos animais são designados a desempenhar. Há, no entanto, pouco conhecimento acerca deste imperativo legal, e alguns estabelecimentos ainda criam dificuldades (HOFFMANN, 1999).

Fato comum entre os usuários de cão-guia é a reclamação pela intolerância de alguns estabelecimentos, tornando um ato inconveniente, já que o cão-guia é um dos recursos para a locomoção de pessoas cegas. Um episódio famoso é o caso da advogada Thaís Martinez e seu cãoguia Boris quando foi impedida de embarcar por estar sem a carteira de identificação do animal, regulamento interno criado pela companhia. $\mathrm{O}$ bloqueio de transitar pelo Metrô de São Paulo resultou na Lei Municipal 12.492/97 (SÃO PAULO, 1997), que assegura o acesso e o trânsito 


\section{$16^{\circ}$ \\ ERGODESIGN USIHC CINAHPA}

de cães-guia em espaços públicos e privados.

Com relação aos recursos didáticos analógicos, de acordo com Cerqueira e Ferreira (2004), os materiais didáticos são de fundamental importância para a educação dos deficientes visuais. Um deles é o braille, formato inventado pelo francês Louis Braille durante o século XIX. Esse método se tornou um dos mais tradicionais por ter uma leitura fácil e dinâmica, podendo ser lida em qualquer idioma. A escrita em braille necessita de uma máquina específica que escreve a partir de combinações de pontos. Cada célula possui 6 pontos de preenchimento e sua leitura é feita com o tato.

O braille possibilita a leitura com a utilização das mãos e pode ser lido em todas as línguas. $\mathrm{Na}$ prática, é necessário passar a ponta dos dedos sobre os sinais de relevo e interpretá-los.

Normalmente, a leitura é feita com a mão direita utilizando um ou mais dedos. Na mão esquerda, os dedos procuram o início da linha seguinte. $\mathrm{O}$ método é subdividido em três graus e cada um deles utiliza de características para leitura na íntegra e com abreviações. As abreviações são aplicadas para diminuir a espessura dos livros e motivar uma leitura com rapidez.

Conclui Baptista (2000) que os livros sonoros e a informática são muito importantes para o desenvolvimento cultural dos cegos, mas nada poderá ou deverá substituir o braille como sistema base da sua educação. Tal como a leitura visual, a leitura braille leva os conhecimentos ao espírito por meio de mecanismos que facilitam a meditação e a assimilação pessoal daquilo que se lê.

Dentre os recursos tecnológicos em uso, conforme Vergara-Nunes, Machado e Vanzin (2011), o método de audiodescrição contribui para a formação intelectual e cultural de forma clara e objetiva, dispõe de todas as informações que os videntes compreendem visualmente. Sua função está presente em ambientes culturais como: filmes, teatros, exposições artísticas e atualmente está presente em cerimônias de casamento. A intenção é descrever todos os pontos que estão sendo captados pelo vidente, tanto questões relacionadas $16^{\circ}$ Ergodesign - Congresso Internacional de Ergonomia e Usabilidade de Interfaces Humano Tecnológica: Produto, Informações Ambientes Construídos e Transporte

$16^{\circ}$ USIHC - Congresso Internacional de Ergonomia e Usabilidade de Interfaces Humano Computador

CINAHPA | 2017 - Congresso Internacional de Ambientes Hipermídia para Aprendizagem. ao tempo e ao espaço quanto a expressões faciais e corporais. A transformação de imagens em palavras acontece entre os diálogos e em suas pausas, nunca se sobrepondo ao conteúdo sonoro relevante, de forma que a informação áudio descrita se harmoniza com os sons do ambiente.

Diferente de outras tecnologias assistivas, a audiodescrição não é um recurso que possa ser adquirido isoladamente e ser utilizado quando o usuário desejar. Trata-se de um recurso veiculado junto com os produtos que, desta forma, passam a ser acessíveis a pessoas cegas. A audiodescrição vem conquistando espaços diversos devido à eficácia com que se apresenta no desafio de traduzir em palavras aquilo que os olhos das pessoas cegas não podem enxergar, mas que os ouvidos podem entender, abrindo espaço para o conhecimento. Como tecnologia assistiva, a audiodescrição "permite às pessoas cegas o acesso a conteúdos visuais, veiculados por qualquer tipo de mídia, pois se trata da tradução em palavras de toda informação visual relevante para a compreensão de uma determinada mensagem" (VERGARA-NUNES; MACHADO; VANZIN, 2011, p. 118).

Segundo Hammerschidt (2008), a tecnologia está presente em dispositivos fixos e móveis de maneira universal, quer dizer que os recursos tecnológicos estão disponíveis para todos e não se difere do equipamento para pessoas que enxergam. Como por exemplo, a interação com o uso do touch screen. O termo se refere ao ato de tocar na tela do dispositivo, utilizando a mão, os dedos ou o auxílio de uma caneta. Disponível em telefones celulares, em tablets, em videogames e em caixas eletrônicas. Porém, grande parte da interação com o usuário se faz pelo contato visual.

O meio que tornou a utilização de equipamentos touch screen universal foi a criação da ferramenta chamada Voice Over criada pela Apple, na tradução livre significa "voz sobre". Os iPhones saem de fábrica com a tecnologia do Voice Over com a função de descrever todas as informações que estão abertas na tela em formato de áudio. Para Android a mesma tecnologia é usada com o leitor Talk Back (FAÇANHA, 2012). 


\section{$16^{\circ}$ \\ ERGODESIGN USIHC CINAHPA}

Uma tecnologia lançada no mercado foi desenvolvida pelo dinamarquês Hans Jorgen Wilberg, é o aplicativo Be My Eyes (ALVES, 2015). Toda a dinâmica é baseada no FaceTime do sistema de iOS, chamadas em videoconferência via internet. O usuário pode se classificar em duas categorias, voluntário ou deficiente visual. A intenção é ajudar os deficientes visuais "sendo os olhos" dele durante alguns segundos. As possibilidades podem ser as mais variadas, desde auxiliar a ler uma data de vencimento de algum produto ou a descrever imagens, lugares e ambientes (ALVES, 2015).

\section{Recursos tecnológicos em estudo}

Novas alternativas tecnológicas surgem a todo instante. Estudos de equipamentos que poderão facilitar a vida dos deficientes visuais são pensados para agregar funções básicas de informação. Algumas já foram divulgadas, outras estão em processo de amadurecimento. Como por exemplo, o anel que lê texto. Conforme Duarte (2014), o anel inteligente, no termo inglês finger reader, é capaz de ler o texto capturando pela câmera e transformado em áudio. Para orientar o usuário, ele transmite vibrações quando a página está no final ou se o dedo sair da linha do texto. O equipamento também disponibiliza um tradutor de texto.

Novidade para impactar socialmente pessoas com deficiências visuais está sendo estudada em Londres. Segundo Lemos (2004), a proposta é fornecer maior autonomia na utilização de transportes públicos, como o metrô. As instruções chegam por meio de áudio e orientam o usuário sobre o espaço, evitando pontos perigosos e o confronto com estruturas e com objetos. Além de fones que emitem vibrações mecânicas através dos ossos intracranianos e ajudam a manter um contato mais apurado com o ambiente. O recurso funciona por meio de um sistema de código aberto com a tecnologia Wayfinder que captura dados do local e envia por beacons via Bluetooth (LEMOS, 2004).

\section{Recursos urbanos}

De acordo com o portal Saúde Visual (2013), o equipamento mais precário em recursos urbanos é $16^{\circ}$ Ergodesign - Congresso Internacional de Ergonomia e Usabilidade de Interfaces Humano Tecnológica: Produto, Informações Ambientes Construídos e Transporte

$16^{\circ}$ USIHC - Congresso Internacional de Ergonomia e Usabilidade de Interfaces Humano Computador

CINAHPA | 2017 - Congresso Internacional de Ambientes Hipermídia para Aprendizagem. o semáforo sonoro. Seu funcionamento é ativado por meio da botoeira sonora, possibilitando a orientação para deficientes visuais com a linguagem em braille. A finalidade do recurso é proporcionar segurança aos pedestres no momento da travessia, sem precisar utilizar a ajuda de terceiros.

A sinalização sonora nos semáforos foi inicialmente implementada para diminuir o número de acidentes fatais de atropelamento que chegava a ser $70 \%$ dos casos nos anos 80 , segundo dados da CET - Companhia de Engenharia de Tráfego. A proposta feita pela CET era impactar todos os pedestres, não só os deficientes visuais, porém, o projeto se contradiz na efetivação. Na época foi instalado apenas um semáforo sonoro, na Rua Conselheiro Brotero, em frente a Associação Laramara (BARONI, 2013). Atualmente, existem cinco semáforos sonoros na cidade de São Paulo, sendo que três estão quebrados. Os semáforos que estão em funcionamento se encontram na região central da capital.

Além dos semáforos, o piso tátil, a superfície tátil, o pavimento tátil ou os podotáteis são recursos presentes nas calçadas, nas estações de metrô, nas novas edificações e nos shopping centers. Com faixas em alto relevo fixadas no chão, elas orientam e alertam o deficiente visual durante a locomoção no trajeto, para indicar rebaixamento de calçadas, desníveis, porta de elevadores, início e término de escadas e rampa (ABNT 9050, 2004). Seu desenho é universal e de fácil reconhecimento.

Segundo a norma técnica (ABNT 9050, 2004), são três as maneiras de aplicar a comunicação e a sinalização na cidade: visual, tátil e sonora. A partir disso há desdobramento para quatro tipos: permanente, direcional, de emergência e temporária.

Para recursos educacionais ou para orientação de espaços públicos de grande circulação, existe o mapa tátil que orienta os deficientes visuais através de informação espacial a dimensão do lugar, as suas características e as alternativas de rota. É essencial que esses mapas sejam acessíveis aos deficientes visuais, e que transmitam informações, 
$16^{\circ}$ USIHC - Congresso Internacional de Ergonomia e Usabilidade de Interfaces Humano Computador

CINAHPA | 2017 - Congresso Internacional de Ambientes Hipermídia para Aprendizagem.

que possam ser lidas com facilidade, através de recursos como o alto relevo e o braile (ABNT 9050, 2004).

\section{Metodologia}

Foi utilizado o método de pesquisa qualitativa e exploratória, conforme descreve Creswell (2007), que trata de reduzir a distância entre indicador e indicado, entre teoria e dados, entre contexto e ação, nos procedimentos de pesquisa de campo. Aplicada com a técnica imersiva etnográfica (ambiente simulado), a pesquisa etnográfica abrange a descrição dos eventos que ocorrem na vida de um grupo com especial atenção para as estruturas sociais e para aos eventos que ocorrem ao seu redor, tendo como amostra da coleta de dados, deficientes visuais.

Fetterman ressalta que a etnografia é mais do que um dia de observação, já que é uma jornada através de um mundo complexo de interação social. O autor define a etnografia como arte e ciência em descrever um grupo ou uma cultura. Complementa que a diferença entre um repórter e um etnógrafo é que o primeiro busca o incomum, a notícia e o segundo descreve uma rotina diária da vida das pessoas de um determinado grupo (FETTERMAN, 1998).

De acordo com Godoy (1995), o etnógrafo precisa ter a habilidade de manter a mente aberta sobre o grupo que está estudando. Antes de entrar em campo, o etnógrafo deve já ter feito um planejamento prévio sobre o problema, a teoria ou o modelo a ser estudado, o desenho da pesquisa, as técnicas de coleta de dados, o material de análise e o estilo de escrita, além de ter a capacitação de analisar esses dados e escrevê-los da maneira mais fidedigna do que foi observado durante sua estadia no campo. Os nomes foram omitidos para manter o anonimato dos integrantes da pesquisa.

\section{Experiência Sensorial: diálogo no escuro}

O pesquisador relata como se dá a convivência do deficiente visual com o mundo. Ressaltando suas dificuldades diárias. Com o objetivo de vivenciar a experiência sensorial proposta pelo local, $\mathrm{o}$ pesquisador fez a visita à exposição Diálogo no Escuro no dia 27 de setembro de 2016.

"Diálogos no Escuro" percorreu grande parte do mundo antes de chegar a São Paulo, em 22 de agosto de 2015. Instalada na Unibes Cultural, a exposição fica na capital do Estado por pelo menos mais seis meses e tem por objetivo a reflexão da população sobre a deficiência visual. A exposição ganhou notoriedade em São Paulo e permaneceu além do tempo hábil, prolongando-se em um ano e meio. $\mathrm{O}$ término esta previsto para 17 de dezembro de 2016.

Idealizada pelo alemão Andreas Heinecke, em 1989, diz que se sente naquela exposição "o paradoxo de aprender a ver de novo através do não olhar". Segundo Andreas, ser cego para ele significa exclusão numa sociedade baseada no visual. Mas não significa infelicidade, graças à recompensa com outro tipo de "olhar", a partir de uma dimensão do cotidiano não visual. No interior da exposição, é possível encontrar ambientes cenográficos, totalmente sem luz, em que o visitante é guiado por pessoas com deficiência visual e passa por uma intensa experiência de tentar entender como os limites são ultrapassados diariamente pelos deficientes visuais. Essas informações foram extraídas do material de divulgação da exposição.

Além de mostrar a importância de respeitar as pessoas com deficiência, o projeto também tem a intenção de gerar empregos por onde passa, pois os guias da exposição são as pessoas com deficiência visual. A visitação pré-agendada acontece com hora marcada e em grupos de no máximo oito pessoas. O grupo desta visitação foi formado por quatro pessoas. A princípio sem se conhecerem, mas após as situações adversas, fizeram laços com $\mathrm{o}$ ato de solidariedade e de altruísmo para que todos tivessem um trajeto correto e tranquilo durante a experiência. A própria guia estimulava comunicação em grupo.

Cada um dos participantes recebe uma bengala e é instruído a usá-la para servir de guia e de varredura. A mesma deve permanecer na mão esquerda enquanto a direita fica livre para tatear 


\section{$16^{\circ}$ \\ ERGODESIGN USIHC CINAHPA}

paredes e objetos. A bengala possui um cordão que a deixa presa ao pulso. Durante a visitação, a bengala pode ser mudada de mão, não devendo ser erguida para não causar acidentes e sempre com movimentos rentes ao chão em semicírculo. Encontravam-se disponíveis duas alturas de bengala. O modelo ideal é a que fica na altura do umbigo do usuário.

Os participantes são guiados pela voz da guia que os acompanhará durante toda a experiência. Ela se apresenta e pede para que cada um se apresente também, falando os nomes e qual o interesse pela exposição. Em seguida, solicita para que sigam sua voz e os conduz ao primeiro ambiente.

\section{Primeiro ambiente: o parque}

Com o auxílio da mão direita, tateando a parede e a bengala varrendo o chão, foi identificado pelos participantes a textura de palha e de folhagens que tocavam os braços. Passando a bengala no chão era possível identificar terra e pedras nos pés. O som ambiente de água e de pássaros caracterizava um lugar natural, com árvores, com água corrente e com cheiro de mato. A guia pede aos participantes para descreverem em que tipo de ambiente se encontram. Todos juntos respondem que estão no meio da natureza.

Com as próprias mãos, a guia auxilia os participantes e os leva até uma estrutura de pedra, pede para que explorem. Está molhada e tem água no fundo, em seu contorno, são percebidos respingos que caem do alto, deve tratar-se de uma fonte. A guia confirma que é uma pequena fonte. $\mathrm{Na}$ sequência do trajeto, sons de uma superfície de metal aguçam a curiosidade. Os participantes se aproximam do objeto que está emitindo o som, tateando um a um a base de metal, percebem que no topo outro objeto é descoberto, com uma forma arredondada. Desconfiam de ser um poste de luz, uma luminária de jardim. A guia confirma que é uma luminária de jardim.

Na sequência, seguindo a voz da guia que orienta o grupo a encontrar um corrimão quadrado de madeira, o chão também muda e começa a balançar e ranger. $\mathrm{O}$ som de água corrente $16^{\circ}$ Ergodesign - Congresso Internacional de Ergonomia e Usabilidade de Interfaces Humano Tecnológica: Produto, Informações Ambientes Construídos e Transporte

$16^{\circ}$ USIHC - Congresso Internacional de Ergonomia e Usabilidade de Interfaces Humano Computador

CINAHPA | 2017 - Congresso Internacional de Ambientes Hipermídia para Aprendizagem. aumenta, percebem que estão em cima de uma pequena ponte sobre um rio. Atravessada a ponte, $o$ grupo se depara com dois objetos. Então, esse grupo se divide em dois. Uma parte senta em um banco de parque e os outros vão até uma escultura de pedra, aparentemente em frente ao banco.

Convidados a tocar uma estrutura que parece uma estátua, tentam descobrir o que seriam aqueles formatos, uma possível cabeça, um ombro, uma cesta e um pássaro. Nos pés, havia uma cesta com três ovos, nas mãos, um objeto, que ninguém consegue identificar. A guia revela ao grupo que é a estátua de João da história infantil "João e Maria".

No mesmo ambiente, o som muda, ruídos de pessoas conversando, buzina de bicicleta se misturam com o som da natureza. Ela questiona se sabem em que ambiente estão. $O$ grupo tenta adivinhar, mas não acertam. Então, percebem que poderia ser um jardim, uma praça ou um parque. A guia revela que estão em uma retratação do Parque do Ibirapuera. Todos os sons do ambiente foram captados no próprio parque, explica ainda que a estátua do João é figurativa, mas que existem inúmeras estátuas no parque.

\section{Segundo ambiente: a feira}

Uma porta se abre e o grupo caminha para o segundo ambiente, amparados pela bengala e tateando as paredes vão tentando se organizar em fileira. Deparam-se com caixotes repletos de legumes e de frutas. $\mathrm{O}$ som característico denunciava que estavam em frente a uma barraca de feira livre. A maneira de identificar os alimentos não é a mesma utilizada pelos videntes. Para saberem quais alimentos estavam nas mãos, além de seu formato singular, alguns poderiam ser confundidos. A instrução dada era para afundarem suas unhas na casca e sentirem o aroma. Ao lado, haviam caixotes com produtos de mercado como: sacos de arroz, feijão, grão de bico e utensílios de higiene. Os visitantes perceberam a complexidade para identificar os produtos e as embalagens de formatos similares, utilizando somente o recurso do tato. Puderam vivenciar a grande dificuldade, pela qual um deficiente visual passa, ao estar 


\section{$16^{\circ}$ \\ ERGODESIGN \\ USIHC CINAHPA}

$16^{\circ}$ Ergodesign - Congresso Internacional de Ergonomia e Usabilidade de Interfaces Humano Tecnológica: Produto, Informações Ambientes Construídos e Transporte

$16^{\circ}$ USIHC - Congresso Internacional de Ergonomia e Usabilidade de Interfaces Humano Computador

CINAHPA | 2017 - Congresso Internacional de Ambientes Hipermídia para Aprendizagem. sozinho em um supermercado sem a ajuda de um vidente.

\section{Terceiro ambiente: a cidade}

Caminhando para o terceiro ambiente, ruídos de carros, buzinas e pessoas falando, pertenciam ao novo cenário que o grupo se encontrava. Tateando as paredes, como se estivessem na calçada de uma rua, sentiram diferentes texturas. Perceberam revestimento frio como azulejos, pastilhas, grades de ferro que poderiam ser associadas aos portões de uma residência. Na sequência, se depararam com a fachada de um edifício, havia um número com três dígitos, a guia os desafiou a dizer que número era aquele. É "803", disseram orgulhosos, após todos tatearem os números e suas formas. Foi de extrema importância manter a calma nesse momento, a fim de perceber os contornos dos números que estavam no alto. Seguindo em direção a rua, descobrem que um piso cheio de bolinhas, era o piso tátil. Significava que a frente deles, havia um obstáculo. A guia orientou que parassem ao término do piso tátil, pois havia um degrau simulando o final da calçada. Ouviram o sinal do semáforo sonoro, indicando o tempo para a travessia. No tempo indicado pelo som do sinal sonoro, o grupo desceu o degrau da calçada e atravessou a rua. Alguns participantes relataram que o ato de descer a guia, só com o auxílio da bengala, foi bastante dificultoso, tiveram a sensação de insegurança.

Terminada a travessia da rua, subiram o degrau da calçada, desta vez sem dificuldades. Agora orientados pelo som de batidas em metal, provocado pela guia, seguiram o som e encontraram um veículo, que ao tocar perceberam que se tratava de uma Scooter. No mesmo lado da calçada, havia um muro com uma caixa de correio e um interfone funcionando. Ao encontrar uma maçaneta na porta, foi possível identificar que se tratava da fachada de uma casa. Novamente, foram desafiados a entender qual era o número daquela residência. Os quatro participantes da exposição disseram em coro "46". Na sequência do trajeto, tateando a parede, foi possível perceber uma superfície lisa de vidro, compreenderam que estavam diante de uma vitrine de loja. No final desta etapa do percurso, foi concluído que o ambiente simulava elementos de uma cidade.

\section{Quarto ambiente: $\mathrm{o}$ boteco}

No quarto e último ambiente, a primeira impressão notada pelo grupo, letras em auto relevo na parede, que ao serem apalpadas e contornadas com as mãos, indicavam a entrada do "Boteco no Escuro". O som ambiente era típico de um bar/restaurante, com música ao fundo, com barulho de pratos batendo, com conversas, com risadas e até com o toque de sineta indicando que um pedido estava pronto. Foram conduzidos pela voz da guia até o balcão. Um garçom interagiu com o grupo e ofereceu três tipos de degustação: bebida, salgado e doce.

Feita as devidas escolhas, a guia os conduz a uma mesa disponível e orienta o grupo batendo com a bengala nos obstáculos, indicando as cadeiras e a mesa. Alguns escolheram saber o que iriam beber, outros se deixaram levar pelo prazer sensorial de descobrir o sabor que estavam consumindo. Todos acomodados surgiram questões por parte de um dos integrantes do grupo. "Como vou saber o local certo para colocar o canudo?", comenta um dos participantes. Com o indicador tateando o topo da embalagem, é possível sentir um desnível na camada da caixinha, que indica o local exato para introduzir o canudo. Acrescentou outro participante. "Fiquem atentos aos aromas, sabores e texturas de suas comidas e bebidas. Agucem o paladar para poderem desvendar o que estão consumindo no bar" - orienta a guia.

Ainda sentados, a guia informa o encerramento da visita, "foram 45 minutos de experiência". Unanimemente, todos se manifestam em dizer como o tempo passou rápido. A guia os convida para uma conversa, aonde surgem as questões sobre adaptações, vivências, e sobre a própria experiência, em um verdadeiro diálogo no escuro.

\section{Entrevista não estruturada em grupo}

Ao término da exposição, dentro do ambiente que simula um boteco, inicia uma conversa aberta com a guia. Informa que todos os guias que trabalham 
$16^{\circ}$ USIHC - Congresso Internacional de Ergonomia e Usabilidade de Interfaces Humano Computador

CINAHPA | 2017 - Congresso Internacional de Ambientes Hipermídia para Aprendizagem.

na exposição são deficientes visuais e ficam disponíveis para responder às perguntas do grupo. São elaboradas uma a uma, de maneira espontânea. A primeira questão levantada foi sobre o espaço e quem pensou na estrutura de interação de um universo desconhecido pelos videntes. A guia responde com propriedade que a ideia foi do alemão Andreas Haineck, em 1989.

\author{
Na época, Andreas recebeu uma \\ incumbência, a de treinar um \\ deficiente visual, tornando o apto \\ a desempenhar tarefas, dentro de \\ um estúdio rádio. Preocupado \\ com a questão da deficiência, \\ decide conhecer a pessoa e vai até \\ seu apartamento, Andreas ficou \\ surpreso ao chegar e notar que o \\ deficiente desempenhava suas \\ tarefas diárias com muita \\ autonomia, ele cozinhava, e \\ andava pelas dependências da \\ residência rapidamente, inclusive \\ o serviu um café (GUIA) ${ }^{\text {. }}$.
}

Tarefas diárias:

Em seguida, outro participante pega o gancho da resposta e pergunta como ela consegue saber a quantidade de ingredientes a ser colocada no preparo de comidas e de bebidas. O exemplo dado foi o preparo do café. Com tranquilidade, ela responde ao grupo que se utiliza do auxílio de medidores, e que no caso do café, já sabe qual quantidade de ingredientes utilizar, para ficar a seu gosto. Acrescenta que o cotidiano e a prática permitem que as tarefas sejam feitas com facilidade ao longo do tempo.

A adaptação é uma das principais características do ser humano, acrescenta e segue para a próxima questão elaborada por outro integrante do grupo que levanta a questão sobre cozinhar utilizando o

${ }^{1}$ Entrevista concedida por GUIA, Exposição da Entrevista I [setembro de 2016]. Entrevistador: Marilu Donadeli Vecchio. São Paulo, 2016. 1 arquivo $\mathrm{mp} 3(75 \mathrm{~min})$. fogão. A guia responde que para ela é tranquilo, pois com o tempo, a pessoa vai adquirindo sua própria técnica, mas antes dessa etapa passou por um processo de reabilitação na Fundação Dorina Nowill. O curso que é disponibilizado para deficientes visuais se chama AVD - Atividades da Vida Diária - no programa são elencadas as necessidades diárias dos deficientes, como aprender a fazer um bolo, uma torta, aprender a se maquiar. São passadas técnicas que ensinarão as pessoas a cozinhar sem se machucar. O exemplo dado pela instrutora foi de como usar o fogão de forma segura.

Eles ensinam a técnica de colocar
a mão acima da chama para sentir
o calor e saber se está aceso, no
caso dos fogões automáticos o
barulho do acendedor indica que
a chama acendeu, mas na dúvida,
usa a técnica de colocar a mão
numa altura segura para não se
queimar (GUIA).

Interação e mobilidade urbana:

Como é feita a adaptação em ambientes culturais, como exposições, salas de cinema e teatros? A guia informa que existem exposições que permitem $\mathrm{o}$ toque em obras de arte em alto relevo. A Pinacoteca foi o exemplo que a guia utilizou, dizendo aos participantes que são permitidos o toque em esculturas e telas, mas somente para os deficientes visuais. "Salas de cinemas estão mais acessíveis por conta da audiodescrição dos filmes, assim como peças de teatro e jogos de futebol", completa a guia. Comenta que gosta de ir a bares e restaurantes. $\mathrm{O}$ barulho excessivo em lugares fechados causa a perda de orientação, como nas baladas. Por outro lado, conhece deficientes visuais que gostam de ir a ambientes com música alta. É uma questão particular do bem-estar de cada um.

Para se locomover por meio de transportes públicos, a instrutora prefere usar o metrô. Segundo ela, para os deficientes, a mobilidade em trens e em metrôs são os melhores transportes, porque há sinalização que possibilita o trânsito seguro. Piso tátil, alerta sonoro, anunciando o nome das estações e jovens cidadãos à disposição 


\section{$16^{\circ}$}

ERGODESIGN

USIHC CINAHPA

para ajudar. Os jovens são adolescentes contratados para auxiliar no embarque e desembarque, comunicam o centro de controle da estação do destino final e disponibilizam outro auxiliar para acompanhar no desembarque. A colaboração também parte dos seguranças das estações e dos próprios usuários.

\section{A orientação sonora dentro das estações já está em fase de teste, na estação Vila Mariana e \\ Pirituba. A orientação sonora informa a próxima parada e a numeração da rua (GUIA).}

Deficiência visual:

A guia inverte os papéis, e pergunta ao grupo, se conhece algum deficiente visual e se sabem auxiliar no momento de oferecer ajuda. A maioria dos participantes respondem que não diretamente, mas que já tiveram contato. A instrutora explica o modo correto de guiar o cego.

O deficiente deve segurar no
braço ou no ombro da pessoa
que o está conduzido, para que
esta possa leva-lo até o local
desejado, ou atravessar uma
rua ou encontrar uma pessoa, e
também orienta o grupo a
nunca segurar na bengala, pois
ela é a maior referência de
espacial do cego (GUIA).

Uma dúvida sobre aguçar os outros sentidos quando se perde a visão surgiu, e a instrutora conta que na verdade a falta de um dos sentidos faz com que os outros sejam mais aguçados, principalmente a audição. A percepção dos sons, das vozes, e o do tato ficam mais apurados, por serem a maior orientação dos cegos.

O grupo questiona sobre a cegueira da guia, perguntando se ela é completamente cega ou se tem algum percentual de visão. "Eu percebo só luz e vultos, tem alguns guias aqui na exposição que são baixa visão, aqueles que têm um percentual de visão menor que $30 \%$, mas eu sou cega total", diz a guia. Em seguida, conta brevemente sua história. $16^{\circ}$ Ergodesign - Congresso Internacional de Ergonomia e Usabilidade de Interfaces Humano Tecnológica: Produto, Informações Ambientes Construídos e Transporte

$16^{\circ}$ USIHC - Congresso Internacional de Ergonomia e Usabilidade de Interfaces Humano Computador

CINAHPA | 2017 - Congresso Internacional de Ambientes Hipermídia para Aprendizagem.

"Eu era baixa visão e acabei perdendo totalmente aos 22 anos. Tenho referência das cores e dos objetos, se vocês disserem estou segurando uma blusa rosa bebê, eu vou saber qual é a cor dela pela minha recordação" (informação verbal 1) acrescenta a guia. Os deficientes visuais que não tiveram essa referência por diversas questões, aprendem cores a sentir as cores por meio do tato, como a grama que pode ser associada a cor verde.

Braille:

O uso do braille é uma curiosidade para os videntes. A habilidade de alguns cegos na leitura do braile, intriga às pessoas, e a pergunta feita para a guia foi, se ela conseguiu se adaptar a esse tipo de leitura. A guia relembra o assunto sobre o processo de reabilitação e explica que aprendeu a andar com a bengala, ler e escrever em braille na Fundação Dorina Nowill. Comenta também, que sua adaptação foi rápida e que aprendeu em quatro meses, a usar e a interpretar o braille.

"A facilidade de encontrar material em braille é grande?", pergunta um integrante do grupo. No Centro Cultural São Paulo, há biblioteca braile e nas instituições Dorina Nowill e Laramara, mas a guia confessa que atualmente ela utiliza o áudio book, recurso de leitura sonora que pode ser utilizada em tablets e em celular. O braille, depois do avanço da tecnologia fícou para trás - confessa a guia.

Mas existe um agravante, a instrutora diz que por usar menos o recurso em braille acaba esquecendo de algumas técnicas, o que afasta ainda mais os usuários da leitura em braille. Outra questão comentada entre os cegos é o volume dos livros. Por ter sua escrita em alto relevo, as publicações tendem a serem pesadas e volumosas dificultando seu manejo e seu transporte.

Tecnologia universal:

Os equipamentos tecnológicos estão atendendo a todas as necessidades de forma universal. A guia fala que seu celular é igual ao dos videntes. A diferença é que ela o utiliza no modo Voice Over, no Iphone e no Talking Back, em Android. Já no 


\section{$16^{\circ}$ \\ ERGODESIGN USIHC CINAHPA}

computador existem softwares de voz. Os pagos custam em média de $\mathrm{R} \$ 1.500,00$ a $\mathrm{R} \$ 5.000,00$. Para a guia fica inacessível e ela opta pelos softwares gratuitos que utilizam o mesmo recurso do celular, lendo tudo o que está na tela.

Acessibilidade e mercado de trabalho:

Questionada sobre qual seria a maior dificuldade em acessibilidade, a guia volta a falar positivamente sobre a tecnologia. "De forma geral, a tecnologia abrange bastante recursos como aplicativos que são acessíveis, sites que estão sendo desenvolvidos com a preocupação de integrar os cegos". Comenta a guia, mas que para ela, a maior dificuldade ainda é a mobilidade urbana. A guia lamenta a má estrutura das calçadas e a falta de semáforos sonoros. Em São Paulo, diz que está melhor do que em outras regiões mais afastadas. A cidade que a guia destacou em exemplos de boas calçadas foi a cidade de Socorro, interior de São Paulo que possui calçadas largas, com piso tátil e estabelecimentos com rampa e com corrimão. "A preocupação em tornar os lugares mais acessíveis é uma constante" comenta a guia, que relembra situações constrangedoras, como na instalação imprudente de piso tátil, que levam ao encontro de paredes, podendo até causar acidentes.

Ao contrário da mobilidade, o mercado de trabalho está mais acessível, segundo a guia, devido a lei de cotas a partir do segundo semestre de 2012. A lei abrange o mercado de trabalho e o ensino superior. No caso dela, além de ser guia/instrutora da exposição, ela atua também no Serasa. A guia encerra o diálogo e conduz o grupo até um último espaço. Agradece a presença e se despede com uma reflexão. "Passamos por uma inversão de papéis, aqui dentro, vocês foram guiados por um cego que conhece o escuro, mas lá fora somos nós que precisamos de vocês".

\section{Considerações finais}

Este artigo procurou relatar as percepções obtidas na experiência do designer digital, quando inserido em um ambiente simulando a falta de visão. $16^{\circ}$ Ergodesign - Congresso Internacional de Ergonomia e Usabilidade de Interfaces Humano Tecnológica: Produto, Informações Ambientes Construídos e Transporte

$16^{\circ}$ USIHC - Congresso Internacional de Ergonomia e Usabilidade de Interfaces Humano Computador

CINAHPA | 2017 - Congresso Internacional de Ambientes Hipermídia para Aprendizagem.
A sua finalidade foi entender as necessidades dos indivíduos com deficiência visual, a fim de estimular o estudo de soluções, que contribuam para tornar mais acessível, mais digna e mais cômoda as atividades do dia a dia das pessoas cegas.

A vivência de estar imerso nas condições de uma deficiência, no caso da exposição a visual, desperta novas responsabilidades de interação social. Com a inversão de papéis, a pessoa que já está acostumada a lidar com a deficiência guia os videntes em um universo até então desconhecido. $\mathrm{O}$ valor da troca de informações mostra a importância do estudo aprofundando para proposta de soluções e de alternativas. A experiência serviu como forma de captar com mais propriedade os pequenos detalhes das necessidades do deficiente visual, a fim de servir como um norte para pesquisa e para estudos dos design digitais, que estão envolvidos com novos projetos para acessibilidade.

Os aspectos de maior relevância, analisados no cotidiano do deficiente visual foram: a locomoção e a comunicação. A urbanização ainda é um dos maiores agravantes na vida dos deficientes. Ao longo dos anos, recursos básicos são implantados, porém numa velocidade inferior à necessária, ao contrário da tecnologia, que avança rapidamente e atinge cada vez mais todos os tipos de usuários, independentemente de ser ou não um portador de deficiência. A comunicação ultrapassa as barreiras do recurso físico e atinge outro nível de interação com o público como, por exemplo, o uso da tecnologia universal.

Logo, tanto a pesquisa quanto a experiência vivida do artigo apontam que o uso das tecnologias universais são as mais aceitas e convenientes, por atenderem às necessidades de seus públicos, sem deixar de lado a democratização na escolha das marcas e da inclusão digital.

Portanto, as melhorias na construção das interfaces acessíveis só serão possíveis com a maximização dos recursos tecnológicos assistivos, uma vez que poderiam ser apliacados a todos os dispositivos disponíveis no mercado. Tal evolução permitiria o 
$16^{\circ}$ USIHC - Congresso Internacional de Ergonomia e Usabilidade de Interfaces Humano Computador

CINAHPA | 2017 - Congresso Internacional de Ambientes Hipermídia CINAHPA para Aprendizagem.

atendimento eficaz e indiscriminado aos usuários especiais.

\section{Referências Bibliográficas}

ABNT 9050. 2004. Acessibilidade a edificações mobiliárias, espaços e equipamentos urbanos. Rio de Janeiro: ABNT NBR, 2004.

ALVES, Paulo. Aplicativo Be My Eyes reúne voluntários que emprestam visão a cegos. 2015. Disponível em:

$<$ http://www.techtudo.com.br/noticias/noticia/2015 /01/app-reune-voluntarios-que-emprestam-visaocegos-conheca-o-be-my-eyes.html>. Acesso em: 23 set. 2016.

BAPTISTA, José Antônio Lages Salgado. A Invenção do Braille e a sua importância na vida dos cegos. Lisboa: CB, 2000.

BARONI, Larissa Leiros. São Paulo tem apenas 2 semáforos sonoros e sem planos de ampliação. 2013. Disponível em:

$<$ http://noticias.uol.com.br/cotidiano/ultimasnoticias/2013/11/18/sao-paulo-tem-apenas-doissemaforos-sonoros-e-nao-tem-planos-deampliacao.htm>. Acesso em: 01 out. 2016.

BATISTA, Claudia Regina. Modelo e Diretrizes para o processo de design de interface web adaptativa. Florianópolis: PPGEGC / UFSC, 2008.

BERSCH, R. Introdução à tecnologia assistiva. Porto Alegre: CEDI, 2008.

BRASIL. Decreto $\mathbf{n}^{0}$ 5296, de 2 de dezembro de 2004. Das Considerações Gerais da Acessibilidade. Capítulo III Artigo $8^{\circ}$. Presidência da República Casa Civilisepi Subchefia para Assuntos Jurídicos.

CERQUEIRA, J. B.; FERREIRA, E. M. Recursos didáticos na educação especial. Instituto Benjamin Constant - Rede Saci, 10 mai. 2004.

CRESWELL, John W. Projeto de pesquisa: métodos qualitativo, quantitativo e misto. Tradução Luciana de Oliveira da Rocha. 2 ed. Porto Alegre: Artmed, 2007.

DUARTE, Henrique. Anel inteligente ajuda cegos a ler textos impressos. 2014. Disponível em: $<$ http://www.techtudo.com.br/noticias/noticia/2 014/04/anel-inteligente-ajuda-cegos-a-ler-textosimpressos-conheca-o-projeto.html>. Acesso em: 06 set. 2016.

FAÇANHA, Agebson R. Uma proposta para acessibilidade visual e táctil em dispositivos touchscreen. 2012. 109 f. Dissertação (Mestrado em Ciência da Computação) - Prograna de PósGraduação em Ciência da Computação, Universidade Federal do Ceará, Fortaleza, 2012.Disponível em:

FERNANDES, Lyerka Kallyane Ramos. Método de pesquisa qualitativa: usos e possibilidades.

Disponível em:

$<$ https://psicologado.com/psicologiageral/introducao/metodo-de-pesquisa-qualitativausos-e-possibilidades>. Acesso em: 26 set. 2016.

FETTERMAN, David M. Etnografia: Passo a Passo. Newbury Park, CA. 1998.

GALVÃO FILHO, T. A. Tecnologia para inclusão social. Revista AREDE. São Paulo: Momento Editorial, n. 53, nov. 2009. Disponível em: $<$ www.arede.inf.br/inclusao /edicoesanteriores/152-edicao-no53-novembro2009/2445-tecnologiaassistiva>. Acesso em: 14 set. 2011 .

GODINHO, Francisco. Internet para

Necessidades Especiais. Vila Real. Portugal: Utad/Guia, 1999.

GODOY, Arilda S. Introdução à pesquisa qualitativa e suas possibilidades. In: Revista de Administração de Empresas. 1995.

GOLDREICH, Daniel. Cérebro compensa perda de visão com velocidade maior na percepção do tato. 2015. Disponível em:

$<\mathrm{http}$ //saudevisual.com.br/noticias/609-cerebro- 


\section{$16^{\circ}$ \\ ERGODESIGN \\ USIHC CINAHPA}

visao-tato>. Acesso em: 02 set. 2016.

HAMMERSCHIDT, Roberto. O que é Touch Screen?. 2008. Disponível em:

$<$ www.tecmundo.com.br/multitouch/177-o-que-etouch-screen-htm>. Acesso em: 06 set. 2016.

HOFFMANN, Sonia B. Benefícios da Orientação e Mobilidade: estudo intercultural entre Brasil e Portugal. Benjamin Constant, Rio de Janeiro, ano 5, n. 14, p. 11-16, dez. 1999.

; SEEWALD, Ricardo. Caminhar sem

Medo e sem Mito. 2003 Disponível em:

$<\mathrm{http}: / / \mathrm{www}$.bengalalegal.com/orienta $>$. Acesso em: 14 set. 2016.

JÚNIOR, Edgar. Rádio ONU. Nova York. OMS afirma que existem 39 milhões de cegos no mundo. 2013. Disponível em:

$<$ https://nacoesunidas.org/oms-afirma-queexistem-39-milhoes-de-cegos-no-mundo/>. Acesso em: 19 set. 2016.

LEMOS, Andre. Cibercultura e Mobilidade: A Era da Conexão. In: Razón y Palabra, n. 41, out./nov. 2004.

MUNARI, Bruno. Das coisas nascem coisas. São Paulo: Martins Fontes, 2000.

OLIVEIRA, Luiza Maria Borges. Cartilha do Censo 2010 - Pessoas com Deficiência. Secretaria de Direitos Humanos da Presidência da República / Coordenação Geral do Sistema de Informações sobre a Pessoa com Deficiência; Brasília: SDHPR/SNPD, 2012.

OMS - Organização Mundial de Saúde. Relatório Mundial sobre a Deficiência. 2013. World Health Organization. The World Bank. Tradução: Lexicus Serviços Lingüísticos. São Paulo.

ONU - Organização das Nações Unidas. Aprova o Programa de Ação Mundial para as Pessoas com Deficiência. Resolução 37/52 da Assembleia
Geral das Nações Unidas, de 03 dez. 1982.

SAUDEVISUAL. Semáforo Sonoro a Luta Continua. 2013. Disponível em:

$<$ http://www.saudevisual.com.br/noticias/219semaforo-sonoro>. Acesso em: 15 set. 2016.

SÃO PAULO. Decreto Lei Municipal 12.492/97. Que Assegura o Ingresso de Cães Guia para Deficientes Visuais em Locais Público ou Privado. 1997.

TUAN, Yi-Fu. Topofilia: um estudo da percepção, atitudes e valores do meio ambiente. São Paulo: Difel, 1980.

VERGARA-NUNES, Elton: MACHADO, Flávia Oliveira: VANZIN, Tarcisio. Audiodescrição como tecnologia assistiva para o acesso ao conhecimento por pessoas cegas. In: ULBRICHT, Vania Ribas; VANZIN, Tarcisio; VILLAROUCO, Vilma (Orgs.). Ambiente virtual de aprendizagem inclusivo. Florianópolis: Pandion, 2011.

Audiodescrição didática. Tese

(Doutorado em Engenharia) - Programa de Pós-

Graduação em Engenharia e Gestão do

Conhecimento, Universidade Federal de Santa

Catarina, Florianópolis, 2016. 